\title{
Above and Beyond the Yearly Wheel: Anticipating and Realizing the Ever-Evolving Contribution of HR
}

\author{
Camilla Ellehave ${ }^{1}$, Dave Ulrich ${ }^{2,3}$ \\ ${ }^{1}$ RBL Nordics, Copenhagen, Denmark \\ ${ }^{2}$ Ross School, University of Michigan, Ann Arbor, USA \\ ${ }^{3}$ The RBL Group, Provo, USA \\ Email address: \\ cellehave@rbl.net (C. Ellehave),dou@umich.edu (D. Ulrich) \\ To cite this article: \\ Camilla Ellehave, Dave Ulrich. Above and Beyond the Yearly Wheel: Anticipating and Realizing the Ever-Evolving Contribution of HR. \\ Journal of Human Resource Management. Vol. 9, No. 3, 2021, pp. 88-93. doi: 10.11648/j.jhrm.20210903.15
}

Received: August 8, 2021; Accepted: August 31, 2021; Published: September 8, 2021

\begin{abstract}
Today's global pandemic, social tensions (racial strife, refuge challenges), political toxicity, economic adversity, and personal emotional malaise challenges will undoubtedly be remembered as a time of unprecedented shock, change, and volatility. The speed, reach, and severity of these crises have accelerated changes about where and how people work, what new organizational systems are required to do work, and how leaders need to act to be effective; all of which are areas of importance to the future of the HR function. While it is critical for HR to respond to the day-to-day administrative requirements caused by these external changes, it is perhaps even more crucial for HR to improve its ability to grasp the consequences of these changes, to anticipate future challenges and their effects. In order to stay relevant and value-adding as a function, HR will need to keep reinventing itself to turn current and future contextual challenges into opportunities. This essay argues that HR will need to keep coming up with new answers to the question: Given these radical, contextual changes, how can HR rise to the opportunity and further improve the function's unique contributions that create value for all stakeholders inside and outside the organization? To answer this question, this essay discusses how definitions of value and business success has changed recently, then goes on to suggest the implications for HR's unique contribution to value creation, delivery, and -capture, and concludes with offering a perspective on the implications for the function responsible for human capability (talent, organization, and leadership). In sum, this article offers business leaders and HR professionals insights on how to anticipate and realize the ever-evolving contribution of HR.
\end{abstract}

Keywords: Contribution of HR, Role of HR, Future of HR, HR Value Added, HR Opportunities

\section{Introduction: New Definitions and Criteria of Business Success}

What defines and drives future business success has changed radically over the past couple of decades. Firmly held beliefs that long-time, successful companies would somehow always be successful has effectively been disproven. More than half of the Fortune 500 companies simply disappeared in the first 15 years after the turn of the century [1]. The concept of "too big to fail", too, has proven itself to be not just wrong but possibly amounting to a dangerous illusion after what you could call some real-life, real-time, intense empirical testing in e.g., the American banking sector $[2,5]$. Future business success is unpredictable and can, thus, no longer be ensured by doing more of the same nor be affirmed by reference to the number of years the company has been in operation nor its revenue size [6].

Another significant shift in what denotes business success has happened simultaneously and perhaps as a consequence of the above changes. Whereas the market value of a business used to be based on its past performances in terms of some financial indicator (ROI, ROIC, EBITDA), the market values of companies are now increasingly also tied to the assessment of their future performance (e.g., number of pending patents, number of planned product launches) [7]. This intangible value has come to represent an increasingly larger percent of a firm's market value [8,9].

After a decade of intense volatility in the financial 
markets, boards of directors, business executives, and investors alike are rethinking the way they define and assess business performance and the value of a business. Instead of focusing on rising share prices, we are searching for indicators of whether a company is fundamentally healthy, and as such, whether the company would be able to sustain its current performance and indeed be able to build profitable businesses in the future [10]. In this sense, investors are turning away from businesses that delivers a reliable, shortterm profit by squeezing the last drops out of their relations to employees and customers, and instead turning to and embracing companies where business and HR leaders are creating a sustainable business - a business where customers, employees, investors, and other stakeholders feel they can trust the organization to act responsibly and deliver results in the future. These shifts create the necessity for business and HR leaders to apply a longer time perspective, mobilize internal and external patience as well as ensuring that their innovation processes are continuously optimized. Only by actively seeking out novel business opportunities better and faster than competition will you be able to create a sustainable and future-proof business.

In parallel, and perhaps even as a response to the changes of the rules of the game mentioned above, the most successful businesses are increasingly also the most innovative businesses [11]. Rapid innovations, new technology and continuously changing customer preferences are disrupting entire industries and changing who ends up winning in the marketplace. The chorus has gone from "Disrupt or be disrupted" to "Disrupt or become Extinct". The implications for business and HR leaders are of course that building and constantly curating the innovative capabilities of a business is no longer optional; it has become a premise for organization survival.

In brief, the radical, imminent global contextual challenges ride on the coattails of a series of significant shifts that have already changed the context in which HR functions operate and which has strongly impacted the definition, role and requirements of successful HR. Gone are the days where business and HR leaders could make their organizations succeed by doing more of the same, apply a short-term and narrow definition of their industries and markets, and where you could decide whether or not to prioritize the development of innovative capabilities.

\section{HR's Unique Contribution to Value Creation, Delivery, and Capture}

The changes described above have caused business and HR leaders to search for ways in which their organizations can adapt faster and more effectively to radical social, political, demographic and technological changes. While there has been a constant need for the HR function to contribute to ensuring the future success of the business for many decades, the ways in which this need has been framed have changed significantly. This is both as a response to the changes in the business contexts mentioned above as well as a general maturity of the HR function. The current business context has, thus, merely increased the urgency for business and HR leaders to find effective responses on how businesses need to operate, to be organized and be led to remain successful.

For the past decades, what has come to denote "HR value creation" has evolved significantly. HR people no longer merely try to "get to the table" and oversee the processes in "the HR yearly wheel". Effective HR professionals deliver value when at the table by challenging and contributing to the development and deployment of the business strategies. HR delivers value through four waves that show a maturation of HR work (see figure 1). HR practices are no longer just about efficiency (wave 1); isolated functional excellence in areas such as staffing, training, reward, digital, analytics, and so forth (wave 2); or even integrated HR solutions to deliver business strategy (wave 3 ). In addition to these waves, HR is increasingly becoming about delivering value to customers, investors, and communities outside the organization (wave 4).

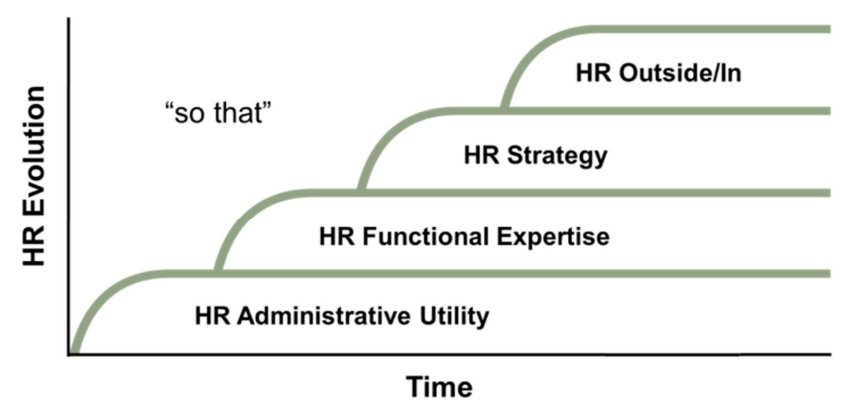

Figure 1. Waves of HR Evolution or Maturity.

The Outside-in wave moves from value delivery to value creation when HR "customers" are not just employees, leaders, or business strategies inside the organization but also stakeholders such as customers, investors (debt or equity), and communities outside the company. HR value creation is realized when the insights about priorities of HR are guided by and contain data and analytics above and beyond internal activities with scorecards, dashboards, and instead actively incorporate insights about the impact of HR activities on the value created for key stakeholders like customers, investors, and communities outside the organization. Furthering this agenda, we have seen a development of how the Outside-in approach is being applied by effective HR professionals. The increased unpredictability of customer preferences, speed of technological innovations and breakthroughs as well as general shifts in political, social and economic developments all affect the Outside. The parameters that need to be patrolled by business and HR leaders to strategize, prioritize and increase the competitiveness and future success of their business - has moved even further away from what used to be thought of as the boundaries of the organization, and has become even more unpredictable and abstract.

The global competitive landscapes are changing more rapidly than ever. Product categories, markets and industries 
are made and made redundant; sometimes almost overnight. Few, if any, businesses are safe from disruptions, and the tasks of business and HR leaders are therefore increasingly becoming how to ensure that the Outside is scanned for ways in which the organizations themselves can disrupt their businesses and/or collaborate with or compete against emerging disrupters. The implications of these changes are fundamental shifts in the role of and requirements to both business and HR leaders.

\section{HR's Unique Contributions to Future Business Success}

HR professionals initiate and are invited to business dialogues because they understand value creation and capture insights from the Outside-in (wave 4). Once in business conversations, HR participates by offering unique contributions in a range of areas. While there are many terms, concepts, tools, practices and actions under the "human resource"-umbrella, we propose a simple yet comprehensive "term sheet" that may help clarify where HR should move going forward, and we also offer a shared blueprint for actions as laid out in the figure below (figure 2).

Human capability is not a new term [12, 13]. Human capability integrates both the individual (human) and organizational (capability) elements of HR's agenda. Many organizations narrowly define HR's role as exclusively focused on individuals with terms like human capital, employee experience, talent manager, and people operations. Other companies have tried to broaden "HR" with "people and organization," which reflects HR's breath of impact. "Human capability", however, takes this widening of the HR field one step further, captures this mix and adds leadership to the blueprint (talent, organization, leadership). These three areas of contribution are not new, and they remain critical for any business' ability to effectively respond to current challenges and discovering future opportunities.
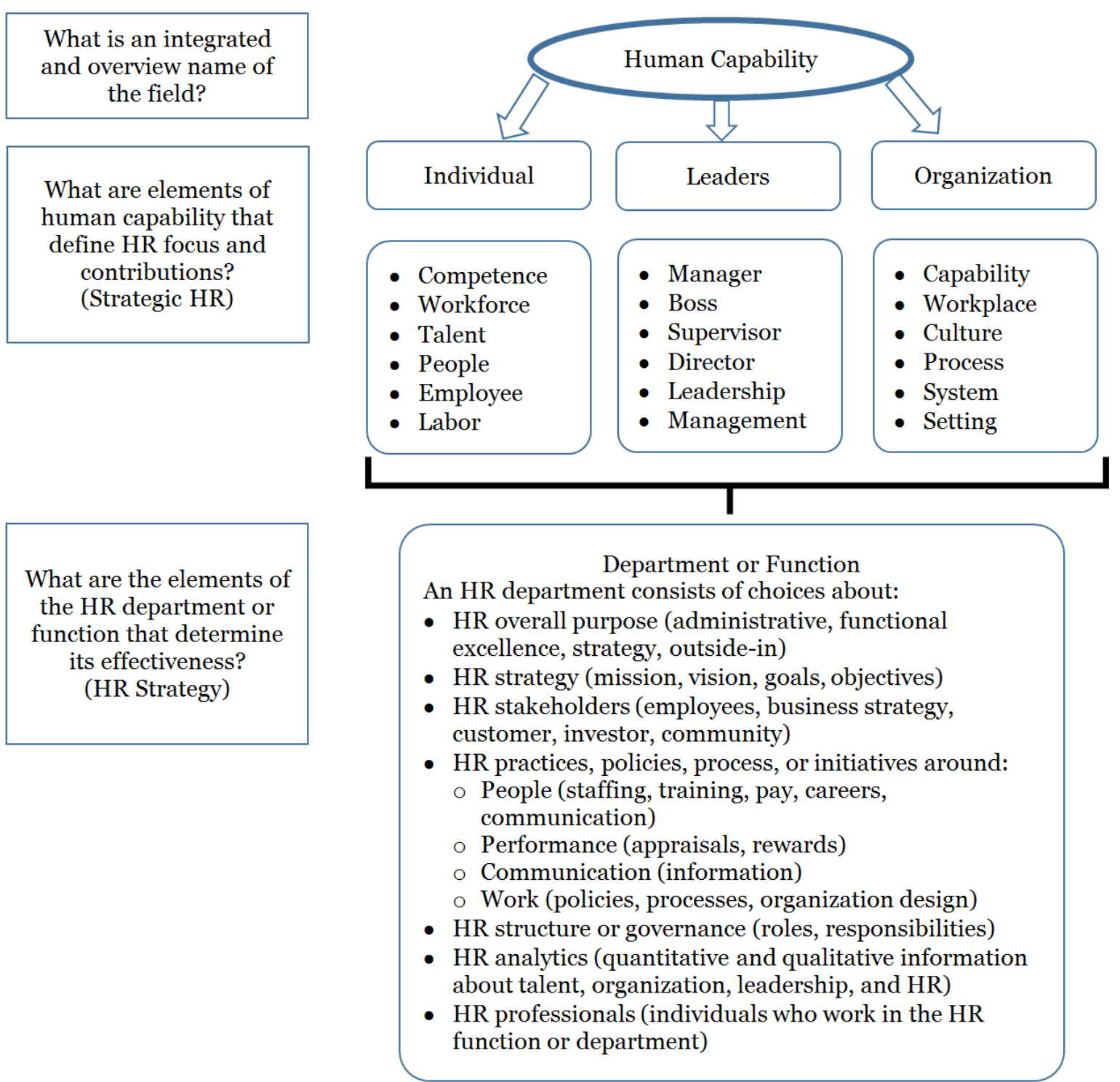

Figure 2. A Blueprint for HR Going Forward. 


\subsection{Human Capability Evolution: Talent}

Traditionally, HR offered unique insights around individual competence or human capital (called workforce, skills, talent, or people). HR's legacy has been to fight the war for talent and focus on ensuring that the right employees were attracted to the organization; the employees had the required competencies (right job, right place, right time), sufficient level of commitment (employee value proposition), and were able to make a contribution. Each of these talent-related efforts can evolve to be viewed Outside-in to respond to changing times by ensuring that the right competencies are those that deliver customer and investor value, and by linking employee experience to customer experience. Many suggest that "people are our most important asset," but today, that should be modified to "our people are our current and future customers' most important asset." HR initiatives that foster the right talent for customers will have a much more lasting impact in a perilous world. As customers adapt their behavior and develop new needs, as e.g. in a dramatic pandemic; talent, too, has to adapt quickly (e.g., using digital information to access product and to manage people virtually). Building employee experience is not enoughHR must create a great employee experience in order to create an improvement to customer experience and investor confidence. Front-runners are already inviting in customers and investors to qualify their talent-improvement initiatives (e.g., inviting customers or investors into hiring, training, compensation, and communication practices), specifically to make sure that their talent practices are continuously adapted to emerging customer requirements.

The recent changes and increased unpredictability of otherwise historically stable industries renders business and HR leaders with an additional task related to Talent. In order to be sufficiently agile, innovative and able to disrupt their own businesses, business and HR leaders need to gain access to, engage and leverage the competencies of an even more diverse group of talents. And, perhaps even more importantly, to determine which types of relations and collaborative methods and technologies that should be applied to do so. Whereas we historically have been referring to a "pool of employees", the time may have come to instead embrace the concept of a "flow of capabilities". The future Talent need of organizations can no longer be satisfied in full by full-time, in office, long-serving employees. The insights and capabilities, which are required to successfully compete and disrupt industries (Scanning the horizon, Out-of-the-box- thinking, Questioning of past solutions and practices, Reframing problems, etc.) are dependent on employees, freelancers, temporary workers, customers, local authorities, investors, and many more groups of people whose only common characteristic is that they can (momentarily or more permanently) be engaged to contribute to realizing the purpose and strategy of the organization.

\subsection{Human Capability Evolution: Organization}

HR also offers unique insights about organizational capabilities (called workplace, culture, or process). Battles are fought by individual people, but wars are won by the organization, which turns individual ingredients into organizational identities. Just like individual personalities (e.g., the big five) are more important predictors of personal well-being than traits (eye or hair color, height, weight), organization capabilities matter more than organizational demographics (number of levels, span of control). Our research on HR competencies and capabilities found that the capabilities of an organization have four times the impact on business results than the competencies of the organization's individuals $[14,15]$. Individuals who work well together as a team will consistently outperform a team of individual allstars, who are not working well together. HR professionals engage leadership teams in defining, developing and deploying the right organization capabilities such as agility, external sensing, innovation, collaboration, or efficiency (Ulrich, 2020). These organizational capabilities are "right" when they are chosen from an Outside-in perspective, and more specifically, applied a version of this perspective that has taken both the dramatically changing world into account and accurately captured the changing definitions of what amounts to value for existing AND potential customers, investors, and communities. Luckily, one thing has not changed: the value of your offering is always defined by the receiver.

With the increase of new types of employee relations (e.g., the gig-economy), less exposure by employees and other organizational resources to anything resembling a common "workplace", and an increased need for innovative capabilities and thinking that challenges rather than solidifies the existing practices of an organization, it would be a serious understatement to claim that our concepts of organization and organizing are in need of further conceptual development. When employees - each with a handful of "jobs" - have been recruited, on-boarded and participated in solving organizational challenges without ever having been in the same physical location as any of their colleagues and quite literally never have had the chance to drink the company cool-aid, it may have changed not just the definition of "employee" but also the requirements to and definitions of engagement, organizing and culture. We are far beyond the concepts of Boundaryless Organizations and perhaps we have also already passed the point where Humanocracy is a viable answer $[16,17]$.

In this period of uncertainty and unpredictability, organizational culture remains a central concept for us to understand and further develop. Just describing a culture (values, behaviors, or roots of a tree) is no longer enough; identifying and ensuring the "right" culture (the fruits and leaves of the tree) that creates, delivers, and captures value for all of the organization's stakeholders (employees, customers and investors alike) is incumbent. 
The shift to defining culture as the identity of the firm in the mind of its existing and potential customers is critical and must shape the employee behaviors and HR practices of the future. In these volatile years, the right organizational culture focuses on customer identity to help organizations stay ahead of and create changes in customer needs rather being focused on printing glossy posters with internal company values.

To fully capture the challenge at hand and for business and HR leaders to tackle the challenge of organizing future organizations in effective, successful and meaningful ways, we may need to replace the concept of "employee" and perhaps even "Human Resources" with "Resources and capabilities accessible and engageable for the organization". The steep incline in need for innovation and diverse thinking, and the factors mentioned above, all add to the complexity of what denotes "an organization" and "organizing". We have probably never been in a situation where there are more moving parts for business and HR leaders alike to identify, attract, engage, coordinate and manage to be able to create futureproof, successful organizations.

\subsection{Human Capability Evolution: Leadership}

Talent and organization are shaped and driven by leaders exhibiting leadership. Employees often mimic what their leaders do, and organizational capabilities often come to reflect senior leaders' preferences and personalities. Leadership at all levels of the organization signals which thoughts and actions that get attention, and lays bare the official - and less official - currencies of the organization. Again the changes in our business contexts and requirements for future successes means that effective leadership of any organization should be derived from what brings about the intended outcomes for the most critical stakeholders: What value can we deliver to existing and potential customers (i.e., what should be our Leadership Brand) (Ulrich \& Smallwood, 2007)? How do we create investor confidence and impact (i.e., how can we improve our Leadership Capital Index) [9]?

In the current uncertain world, it is undoubtedly more important than ever to ensure that the right leadership exists and are able to create value for an increasing number and increasingly diverse group of stakeholders, while prioritizing existing and potential customers, attracting and engaging resources of all sorts and satisfying an increasing number and diverse range of investor expectations.

In Leadership Code, we concluded that the main parts of Leadership competencies are generic across level, industries, geographies, etc. Business Leaders need to attend to the short- and the long-term; and to the business as well as the people involved $[18,19]$. We still find these distinctions helpful to grasp the challenges and practices of leadership. And yet, we also recognize that there may be a need to rethink some of the ways in which we practice leadership in these radically changed contexts and conditions; specifically how we strategize and organize.

When leaders can no longer deliver the necessary value to stakeholders and drive business results by doing more of the same, no longer (has to) know the right answers - and are perhaps even scrambling with the rest of the Sprint-Team to ask the right questions, no longer have access to a stable and predictable pool of employees, and are expected to actively and deliberately disrupt the products, markets and industries their business are operating in, it must be the understatement of a century to claim that the rules of the leadership game have changed [20].

We will need the HR function to focus on and solve the challenge of how we can enable our leaders to effectively identify, attract, engage, retain and recycle the required resources and capabilities - not to mention; foster their effective collaboration - to enable the growth and success of the organization.

And we need to assist the leaders in finding methods and processes to accept and facilitate the use of a lot of more moving parts and fluidity of organizing as part of tomorrow's business context, which of course will also challenge and change the requirements for the selection and development of the very same leaders.

\section{Conclusion: HR's Ever-Evolving Contribution}

Effective HR professionals successfully engage in business discussions in today's changing world because the value they add to the future success of the business is acknowledged not only inside but also outside the organization (four waves). HR professionals more fully contribute and have a business impact because they create, deliver, capture and deploy valuable insights on talent, organization, and leadership, and do so with a keen eye on the forces and dynamics roaming on the Outside of the organization.

Today's business context will likely be long remembered for the crises our world has faced. Hopefully, they will also be remembered as a time when HR insights on talent, leadership, and organization enabled employees to find wellbeing; organizations to deliver digital and other strategies; customers to continue receiving products and services; investors to keep confidence, and communities to thrive through increased social citizenship.

\section{References}

[1] Bonnet, D. et al. https://www.capgemini.com/consulting/wpcontent/uploads/sites/30/2017/07/digital_disruption_1.pdf

[2] Dash, Eric (2009-06-20). "If It's Too Big to Fail, Is It Too Big to Exist?". New York Times.

[3] Stern, Gary H. \& Feldman, Ron J. (2004). Too big to fail: the hazards of bank bailouts. Brookings Institution Press. ISBN 978-0-8157-8152-3.

[4] Turner, Adair (2010). "Too Much 'Too Big to Fail'?" Economist's View. September 2, 2010. 
[5] Gup, E. (ed.) (2003). Too Big to Fail: Policies and Practices in Government Bailouts. Westport, Connecticut: Praeger Publishers. p. 368. doi: 10.1336/1567206212. ISBN 978-156720-621-0. OCLC 52288783.

[6] Ellehave, C.; Burns, E. W. \& Ulrich, D. (2021), "Embracing and Harnessing Uncertainty". In Byrd-Poller, L.; Farmer, J. L. \& Ford, V. (Eds), Role of Leadership in Facilitating Healing and Renewal in Times of Organizational Trauma and Change. IGIGlobal.

[7] Koller, T.; Goedhart, M. and Wessels, D. (2005). Valuation: Measuring and Managing the Value of Companies, fourth edition, Hoboken, New Jersey: John Wiley \& Sons, 2005.

[8] Dave Ulrich and Norm Smallwood. 2004. Capitalizing on capabilities. Harvard Business Review. 119-128.

[9] Ulrich, D. (2015). The Leadership Capital Index: Realizing the Market Value of Leadership. Berrett-Koehler Publishers, Oakland, CA.

[10] Dobbs, R. \& Koller, t. (2005). https://www.mckinsey.com/business-functions/strategy-andcorporate-finance/our-insights/measuring-long-termperformance\#

[11] Yeung, A. \& Ulrich, D. (2019). Reinventing the Organization. Harvard Business Review Press, Boson, MA.

[12] Jacques, E \& Carson, K. (1994). Human Capability. London: Gower.
[13] Wright, P., \& McMahan, G. (2011). Exploring human capital: Putting 'human' back into strategic human resource management. Human Resource Management Journal, 21 (2), 93-104.

[14] Ulrich, Dave, David Kryscynski, Wayne Brockbank, Mike Ulrich. 2017. Victory Through Organization: What the war for talent is failing your company and what you can do about it. New York: McGraw Hill.

[15] Wright, Patrick, Mike Ulrich, Erin Burns. 2021. HR competency study, round 8 . https://www.rbl.net/hrcs-round-8.

[16] Ashkenas, R. N. (2002). The boundaryless organization: Breaking the chains of organizational structure. San Francisco, CA: Jossey-Bass.

[17] Hamel, G. \& Zanini, M. (2020). Humanocracy: Creating Organizations as Amazing as the People Inside Them. Harvard Business Press, Boston, MA.

[18] Ulrich, D. \& Smallwood, N. (2007a). Leadership Brand: Developing Customer-Focused Leaders to Drive Performance and Build Lasting Value. Harvard Business Review Press, Boston, MA.

[19] Ulrich, D. \& Smallwood, N. (2007)b. Leadership Code: Five Rules to Lead. Harvard Business Review Press, Boston, MA.

[20] Ulrich, D. (2020). Knowing Which Organization Capabilities Make a Difference. https://www.linkedin.com/pulse/knowingwhich-organization-capabilities-make-dave-ulrich/ 